\title{
Cattle Management System: A Case of Pakistan
}

\author{
Asif Siddique $^{1} \quad$ Fiaz Hussain $^{1} \quad$ Muhammad Naeem $^{1} \quad$ Aftab Ahmed $^{2} \quad$ Shafqat Naeem ${ }^{1}$ \\ Ghazanfar Ibrahim ${ }^{1}$ \\ 1.Department of Computer Science \& IT, Ghazi University, Dera Ghazi Khan, Pakistan \\ 2.Department of Computer Science, University of Lahore, Pakistan
}

\begin{abstract}
The aim of the project is to provide various services to the buyers like they can select the cattle of their choice to buy or also they can sell any of their cattle on the website at the desirable selling price. Cattle Management System is a web based application that allows the administrator to handle all the activities online like selling and purchasing of various animals by the needful people quickly and safely. Using Interactive GUI anyone can quickly learn to use the complete system. Using this, the administrator doesn't have to sit and manage the entire activities on paper and at the same time, the head will feel comfortable to keep check of the whole system just with the availability of internet. This system will give him power and flexibility to manage the entire system from the single online portal.
\end{abstract}

Keywords: Cattle Management System, Online Sale Purchase, Ghazi Farm, Web Applications

DOI: $10.7176 /$ JIEA/9-6-03

Publication date:October $31^{\text {st }} 2019$

\section{Introduction}

The purpose of the document is to collect and analyze all assorted ideas that have come up to define the system, its requirements with respect to users. The aim of the project is to provide various services to the buyers like he can select the cattle of their choice to buy or also they can sell any of their cattle on the website at the desirable selling price [1].

The current system is offline system. So this current system is very difficult because its time consuming. So our project aims at creating a web application which tracks cattle records, online purchasing, online selling etc [2].

\subsection{Objectives}

1. The system should have a user registration process in order to get login into the system.

2. The system should have a administrator login page .

3. The system will show cattle which available on web.

4. Administrator can display the request of user successful.

\section{Technical Feasibility}

Technically, this project is very feasible because of use of current and latest techniques. I have already done this type of projects using latest technologies like making front end in the bootstrap, Html 5, CSS 3, java script and JQuery and backend development will be done in very efficient tool MySQL database. So this project is technically feasible.

\subsection{Existing System: Data Analysis}

Objectives

- To document the physical existing current system.

Responsibilities

- The Analysts draw a set of Function Charts, preliminary Entity-Relationship diagrams and Physical Existing DFD's to describe the existing systems.

Inputs

- Existing documents, publications and other written material.

- Existing system specifications.

- Organization charts.

\section{Method}

- Develop a set of Function Charts defining the functions, and current approaches of the organization. These are a refinement of the Function Charts developed during Systems Planning and Architecture Definition. Be aware that Function Charts by their nature are intended to be 'logical', and therefore do not include redundant functionality [3].

- Draw a preliminary Entity-Relationship model showing the key entities of interest to the current systems.

- Prepare physical Data Flow Diagrams of the existing system(s) Preparing these DFD's. 
- Helps to determine who the users are

- Ensures that no functionality is inadvertently omitted

- Indicates areas potentially impacted by the introduction of a new system

- Helps users become comfortable working with DFD's since their terminology and concepts

- Is a tangible demonstration to users of the analyst's understanding of the existing environment

- When documented competently, helps to increase the users' confidence it the analyst and, consequently, in the project.

- Identify the files, which represent the existing data entities, and the Data Flows (inputs and outputs), which represent the physical User Views of the existing system.

These should be used to produce a rough Data Model of the data used by the existing system.

Working Documents

- Physical Existing Data Flow Diagrams Function Charts (hierarchical representation of system processes)

- Preliminary (Current/Existing) Logical Data Flow Diagrams

Tools

Only use these tools if the DFD's will be presented to the users, otherwise hand-drawn diagrams are sufficient. A lot of effort is required to draw a DFD regardless of the tool used. However, automated tools make it possible to make changes to DFD's more quickly. Analysts should assume that changes will be made since drawing DFD's is still somewhat of an art, and analysis is an iterative process [4].

Deliverables

Function Charts Data Model of physical existing data usage. Physical Data Flow Diagram of the existing system. Preliminary logical Data Flow Diagrams of the existing system.

\section{Variations}

Although data gathering and the production of Function Charts and DFD's are presented here as separate tasks in chronological order, they in fact occur concurrently. Analysts draw DFD's as they are collecting data, and return to gather more data as they are drawing DFD's.

\section{Systems Analysis Methodology Overview}

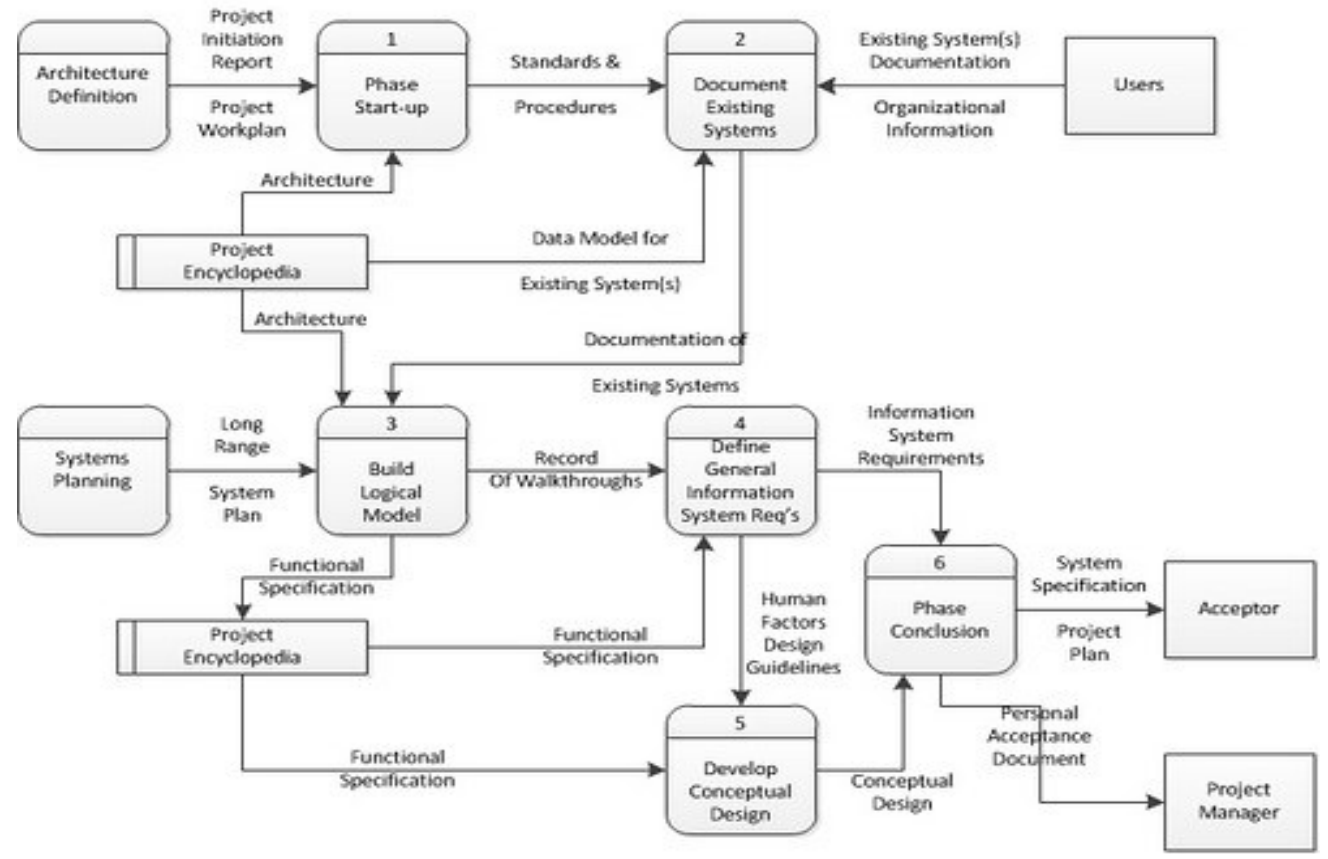

Figure 1: (system Analysis Methodology Overview)

\subsection{Data Flow Diagrams (DFDs)}

A data flow diagram (DFD) is a graphical representation of the "flow" of data through an information system, modeling its process aspects. A DFD is often used as a preliminary step to create an overview of the system, which can later be elaborated. DFDs can also be used for the visualization of data processing (structured design). Data flow diagrams are also known as bubble charts. DFD is a designing tool used in the top-down approach to Systems Design. This context-level DFD is next "exploded", to produce a Level 1 DFD that shows some of the detail of the system being modeled. The Level 1 DFD shows how the system is divided into sub-systems (processes), each of which deals with one or more of the data flows to or from an external agent, and which 
together provide all of the functionality of the system as a whole. It also identifies internal data stores that must be present in order for the system to do its job, and shows the flow of data between the various parts of the system [5].

There are four level data flow diagram of Ghazi Farm. They are as follows:-

- Zero Level Data Flow Diagram (0 Level DFD)

- First Level Data Flow Diagram (1st Level DFD)

\subsection{Zero Level Data Flow Diagram (0 Levels DFD) Of Ghazi Farm:}

This is the Zero Level DFD of Ghazi Farm, where we have elaborated the process of cattle manage. It's a basic overview of the whole Ghazi Farm or process being analyzed or modeled.

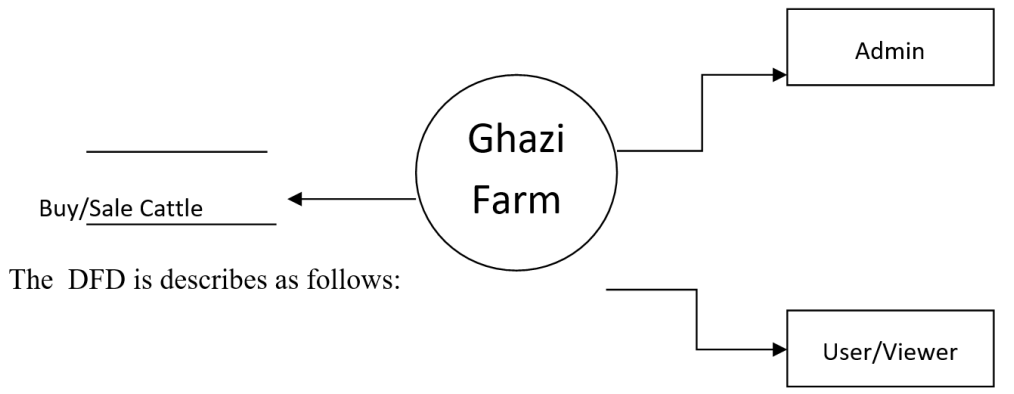

Figure 2: Data Flow Diagram Level 0

\subsection{First Level Data Flow Diagram (1st Level DFD) Of Ghazi Farm:}

First Level DFD (1st Level) of Ghazi Farm shows how the system is divided into subsystems (processes), each of which deals with one or more of the data flows to or from an external agent, and which together provide all of the functionality.

It's designed to be an at-a-glance view of Login, view cases, Search showing the system as a single highlevel process, with its relationship to external entities of cases, Uploads and Login.

It should be easily understood by a wide audience, including cases, Uploads and Login. In zero level DFD of Ghazi Farm, we have described the high level flow of the Ghazi Farm.

Entities and process flow of Ghazi Farm:

- Managing all the Uploads

- Managing all the Contact

- Managing all the Cattles

- Managing all the Category

- Managing all the Subcategory

- Managing all the Login

- Managing all the Admin

- Managing all the Users

\section{Data Flow Diagram Level 1}

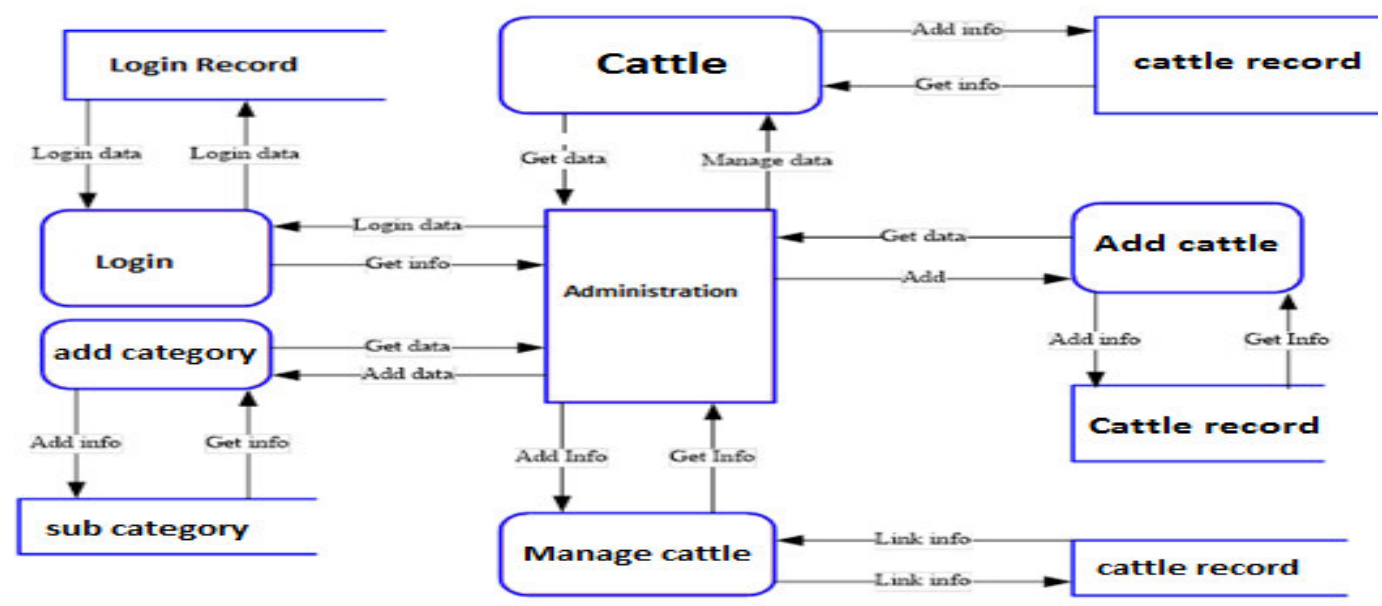

Figure 3: (Data Flow Diagram Level 1)

Requirements engineering activities

The activities involved in requirements engineering vary widely, depending on the type of system being 
developed and the specific practices of the organization(s) involved. These may include:

1. Requirements inception or requirements elicitation

2. Requirements identification - identifying new requirements

3. Requirements analysis and negotiation - checking requirements and resolving stakeholder conflicts

4. Requirements specification (e.g., software requirements specification; SRS) - documenting the requirements in a requirements document

5. Systems modeling - deriving models of the system, often using a notation such as the Unified Modeling Language (UML) or the Lifecycle Modeling Language (LML)

6. Requirements validation - checking that the documented requirements and models are consistent and meet stakeholder needs

7. Requirements management - managing changes to the requirements as the system is developed and put into use

These are sometimes presented as chronological stages although, in practice, there is considerable interleaving of these activities.

\section{Use Case Diagram}

A use case diagram in the Unified Modeling Language (UML) is a type of behavioral diagram defined by and created from a Use-case analysis. Its purpose is to present a graphical overview of the functionality provided by a system in terms of actors, their goals (represented as use cases), and any dependencies between those use cases. The main purpose of a use case diagram is to show what system functions are performed for which actor. Roles of the actors in the system can be depicted. The main purpose of a use case diagram is to show what system functions are performed for which actor. Roles of the actors in the system can be depicted.

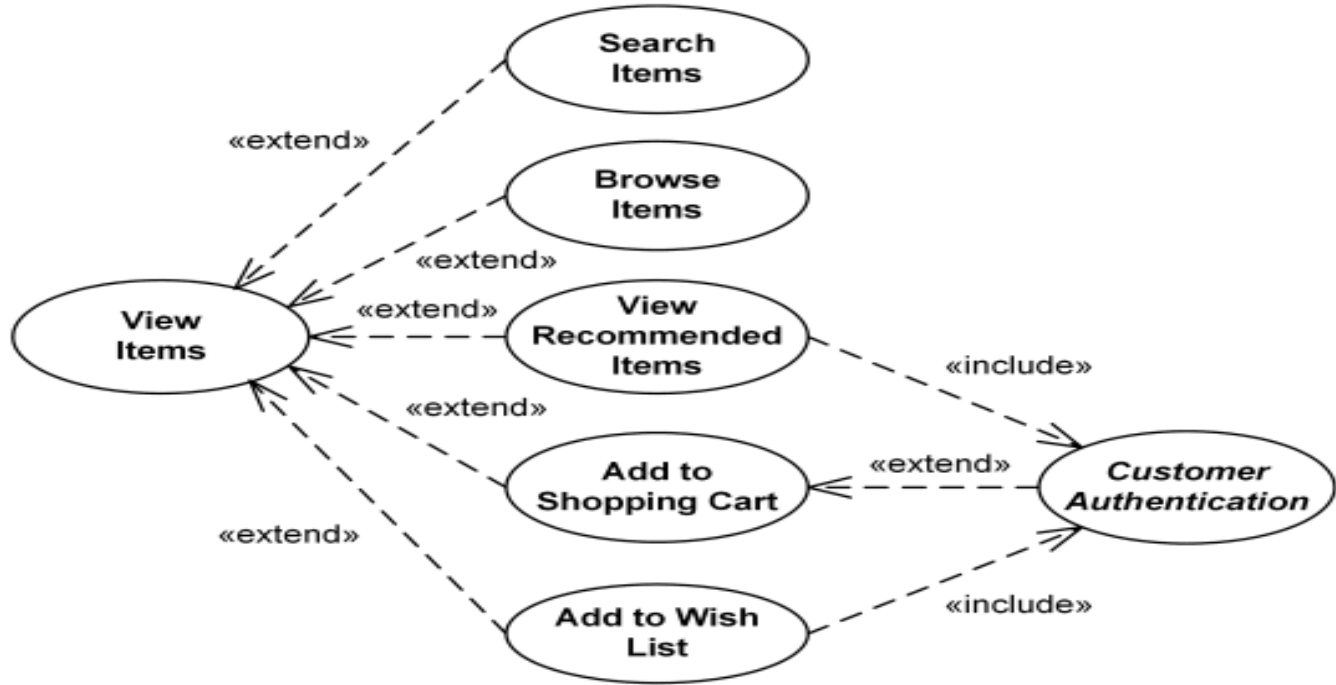

Figure 4: (Use Case Diagram)

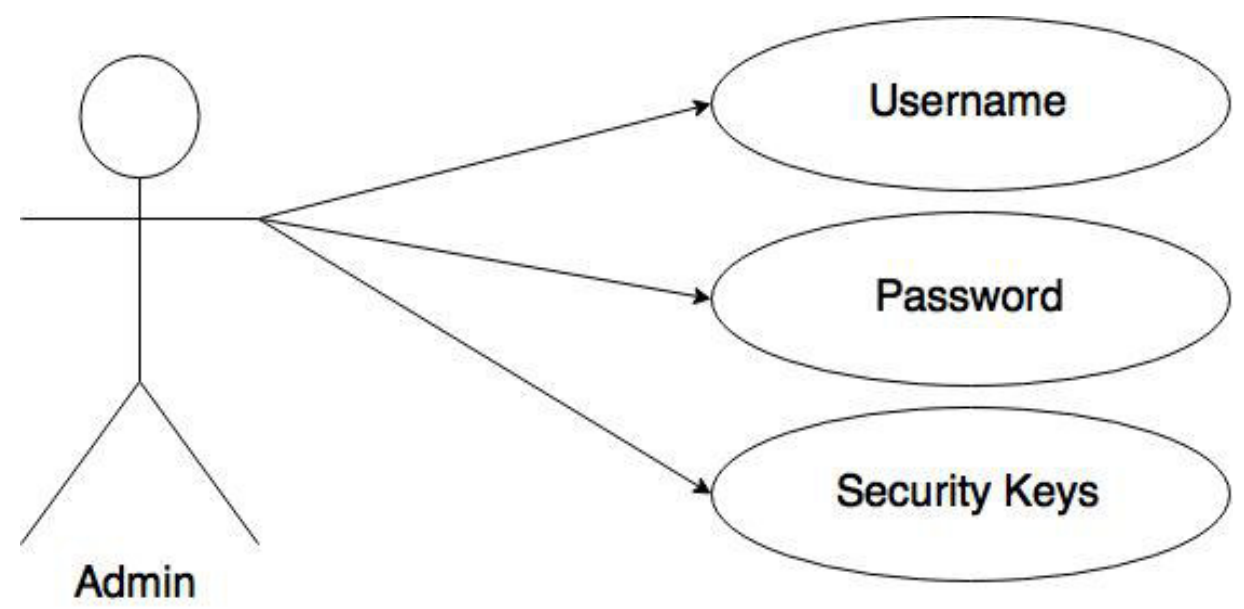

Figure 5: (Entering admin into system) 


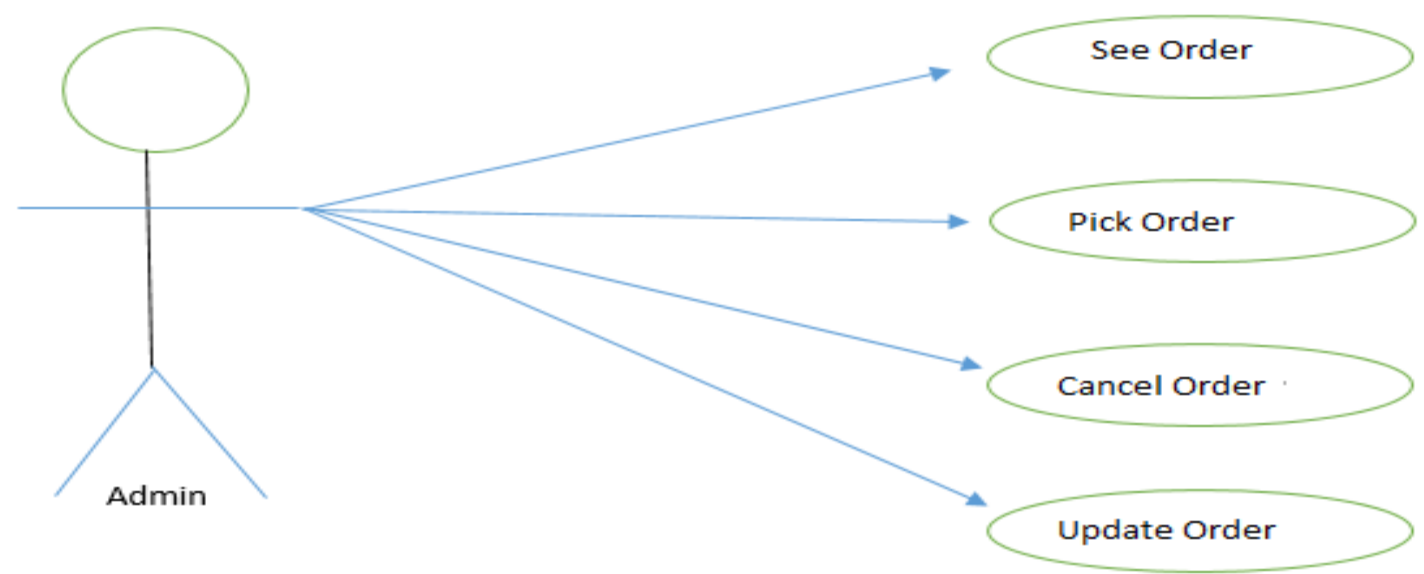

Figure 6: (Maintaining order into system)

\subsection{Admin Side}

As this application is actor based so the site plan is according to the roles of the actors.

1. Admin Login

2. Edit Cattle Details.

\subsection{Buyer/Seller Side}

1. Signup Page

2. Sign in Page

3. Pages that meet in the cattle Application Level

\subsection{Data Base Administrator}

1. Full Control Over Database

2. Add/Update/Delete/view cattle Record

3. Add/Update/ Delete/view cattle category

4. Add/Update/Delete/view cattle order

5. Add/Update/Delete/view users

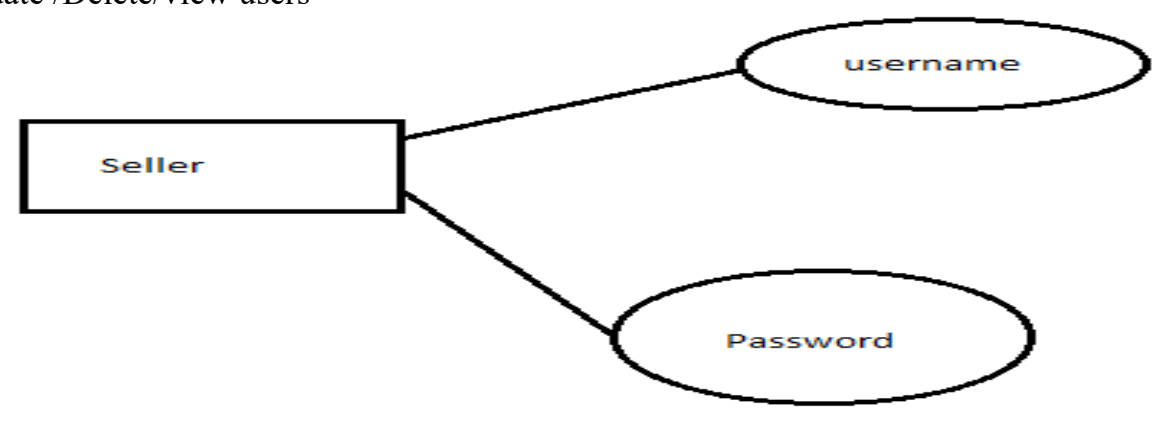

Figure 7: (Entering seller into system)

\subsection{Database Modeling}

Name

LOGIN_ID

PASSWORD

LOGIN_TYPE

USERANAME

CREATE_DATE

\section{LOGIN TABLE}

NOT NULL V VARCHAR (25)

VARCHAR (25)

INTEGER

VARCHAR (25)

DATE 


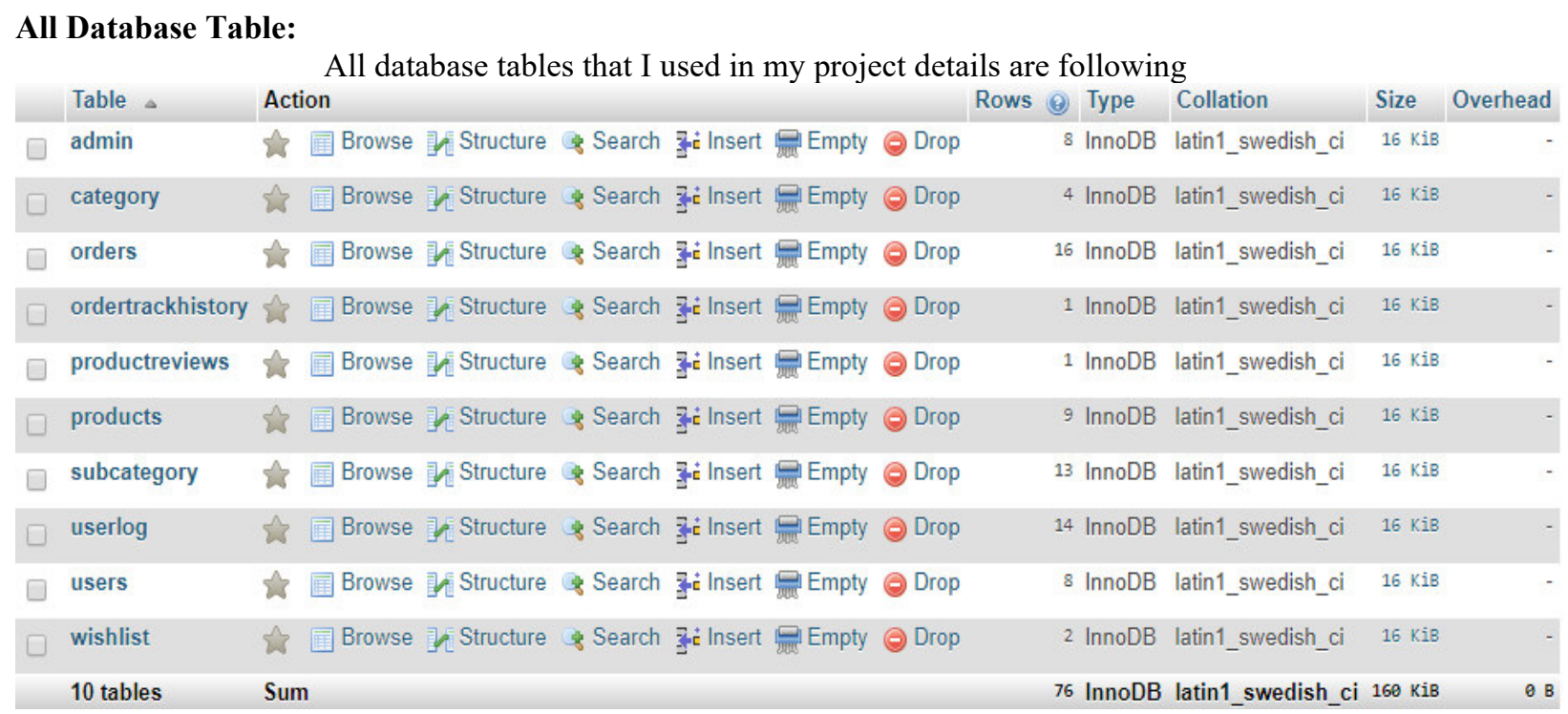

Figure 8: (All tables of database)

\section{Tool/Language Selection}

Tools are always selected on your requirements. Many problems are faced while understanding the working of this project. Selection of the appropriate software for the development of the system is the most crucial stage of the system design. The choice of the software tool should be carried out keeping in view the problem at hand in order to avoid heavy loss of time.
* HTML, CSS, PHP, MYSQL, JAVA SCRIPT
* MS WORD, SUBLIME, XAMPP

\section{Test Results}

Fallowing results has been shown:

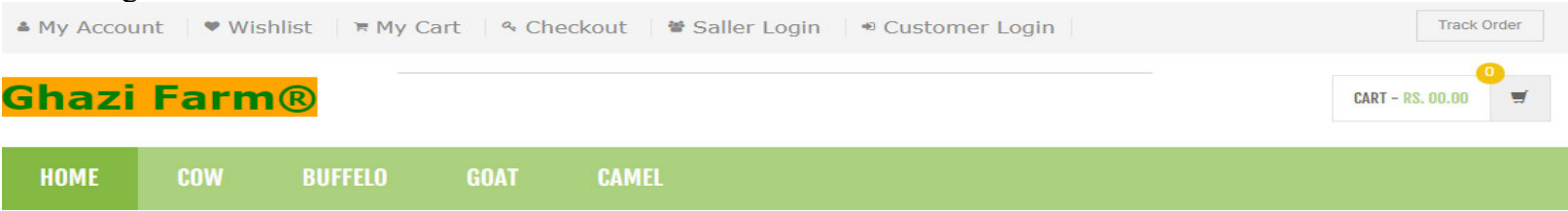

\begin{tabular}{lll}
\hline$\equiv$ & CATEgORIES & \\
$\square$ & COW & $\circ$ \\
$\square$ & BUFFELO & $\circ$ \\
$\square$ & GOAT & $\circ$ \\
$\square$ & CAMEL & $\circ$
\end{tabular}

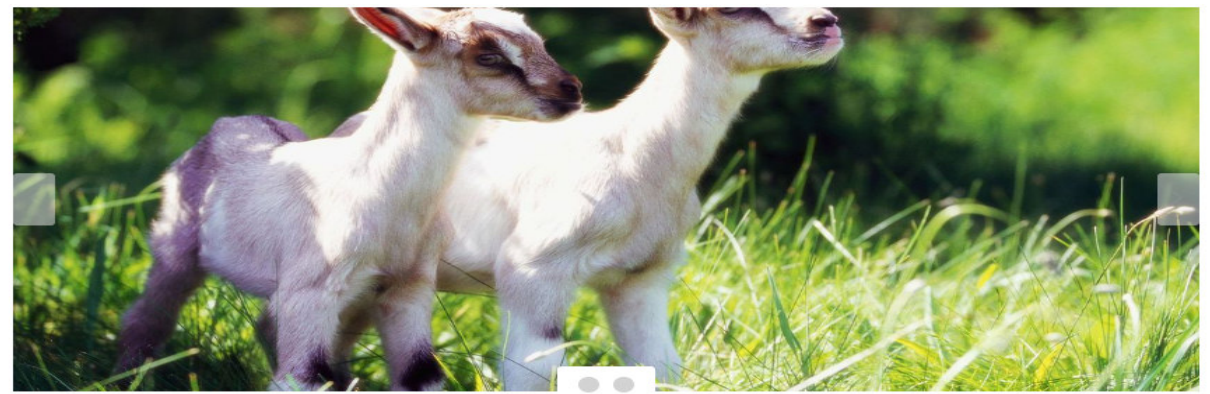

Figure 9: (Home Page) 


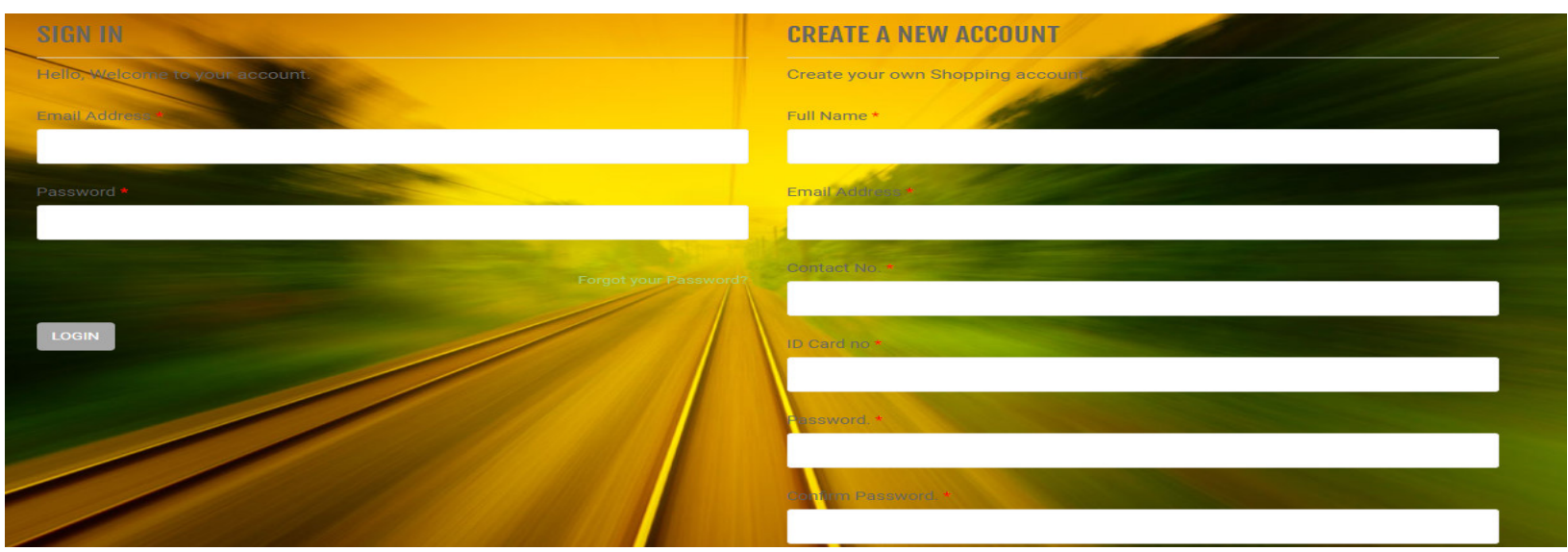

Figure 10: (Registration Form)

Ghazi Farm | Seller

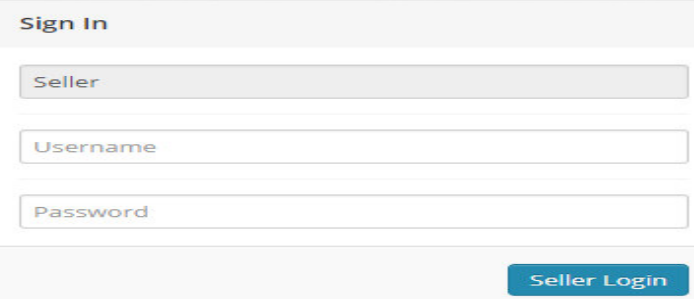

Figure 11: (Login Seller)

Ghazi Farm | Admin

Sign In

Username

Password

Figure12: (Login Admin) 

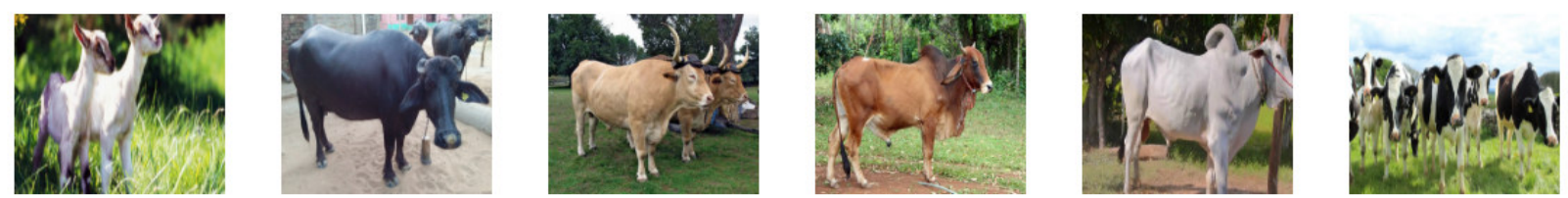

\section{Ghazi Farm ®}

Ghazi Farm (8) is No\#1 cattle service provider in Pakistan. Dairy Farm International Holdings Limited is incorporated

(f) in $\mathrm{B}$ (
OPENING TIME

Monday-Friday:

Saturday:

Sunday:
08.00 To 18.00

09.00 To 20.00

10.00 To 20.00

. Figure 13: (Contact us)

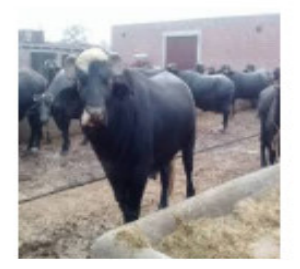

Neeli

Rs. 80000

Add to Cart

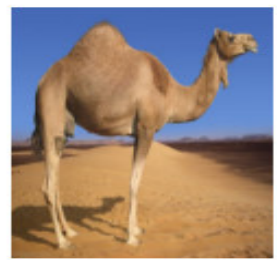

camel

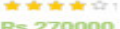

Adet to Cart

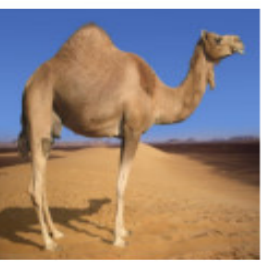

camel

Add to Cart

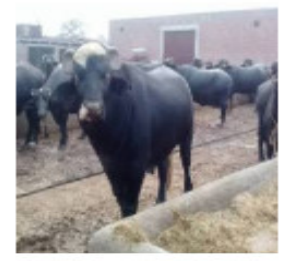

Neeli

का 1 का

Rs. 80000

Add to Cart

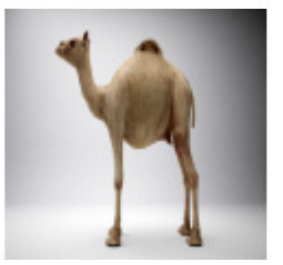

camel

w\#\#\#西

Rs.250000

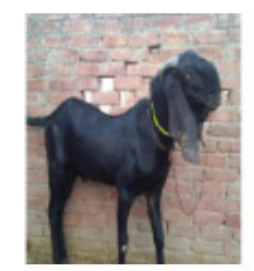

Bakra

$-7=-12$ Rs.7000 मa
INFORMATION

(9) Model Town, DG Khan

(+92) 3024545454 (+92) 3112222112

info@ghazifarm.com

Figure 13: (Home page user) 


\section{Ghazi Farm $®$}

HOME GOW BUFFEL GOAT CAMEL

E CATEGORIES
$\square \quad$ COW
$\square \quad$ BUFFELO
$\square \quad$ GOAT
$\square$ CAMEL

Ghazi Farm ${ }^{\circledR} \mid$ Admin

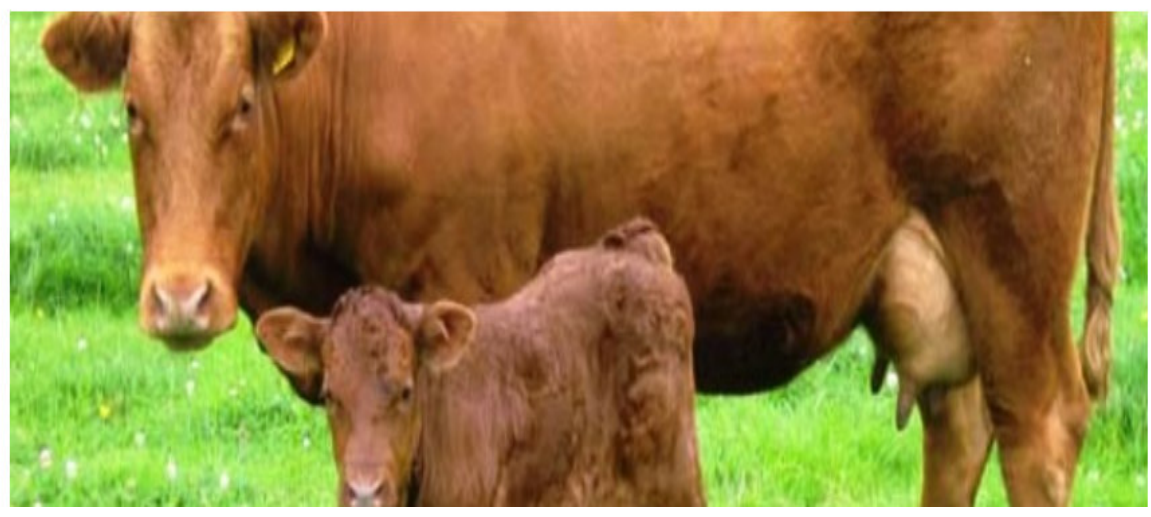

Figure 14: (Categories)

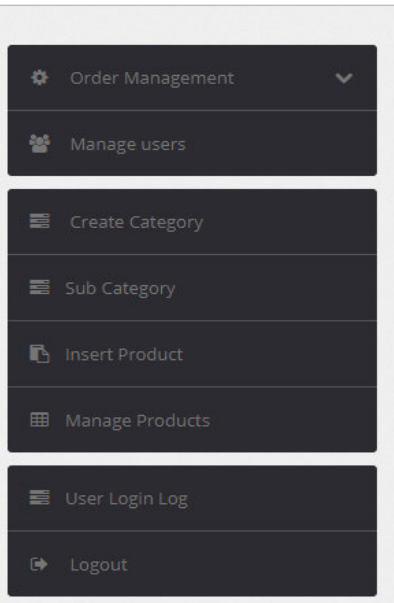

Category

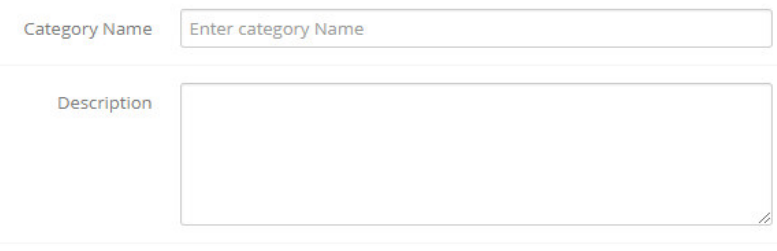

Create

Manage Categories

\begin{tabular}{|c|c|c|c|c|c|}
\hline \multirow{2}{*}{$\begin{array}{l}\text { Show } \\
\#\end{array}$} & \multicolumn{2}{|l|}{10} & entries & \multicolumn{2}{|l|}{ arch: } \\
\hline & Category & Description & Creation date & Last Updated & Action \\
\hline 1 & Cow & & 2018-07-19 03:05:29 & & {$[0$} \\
\hline 2 & Buffelo & & 2018-07-19 03:05:38 & & $\mathbb{0} 0$ \\
\hline 3 & Gnat & & $2018-07-19 \cap 2: 05: 45$ & & 50 \\
\hline
\end{tabular}

Figure 15: (Add Categories) 


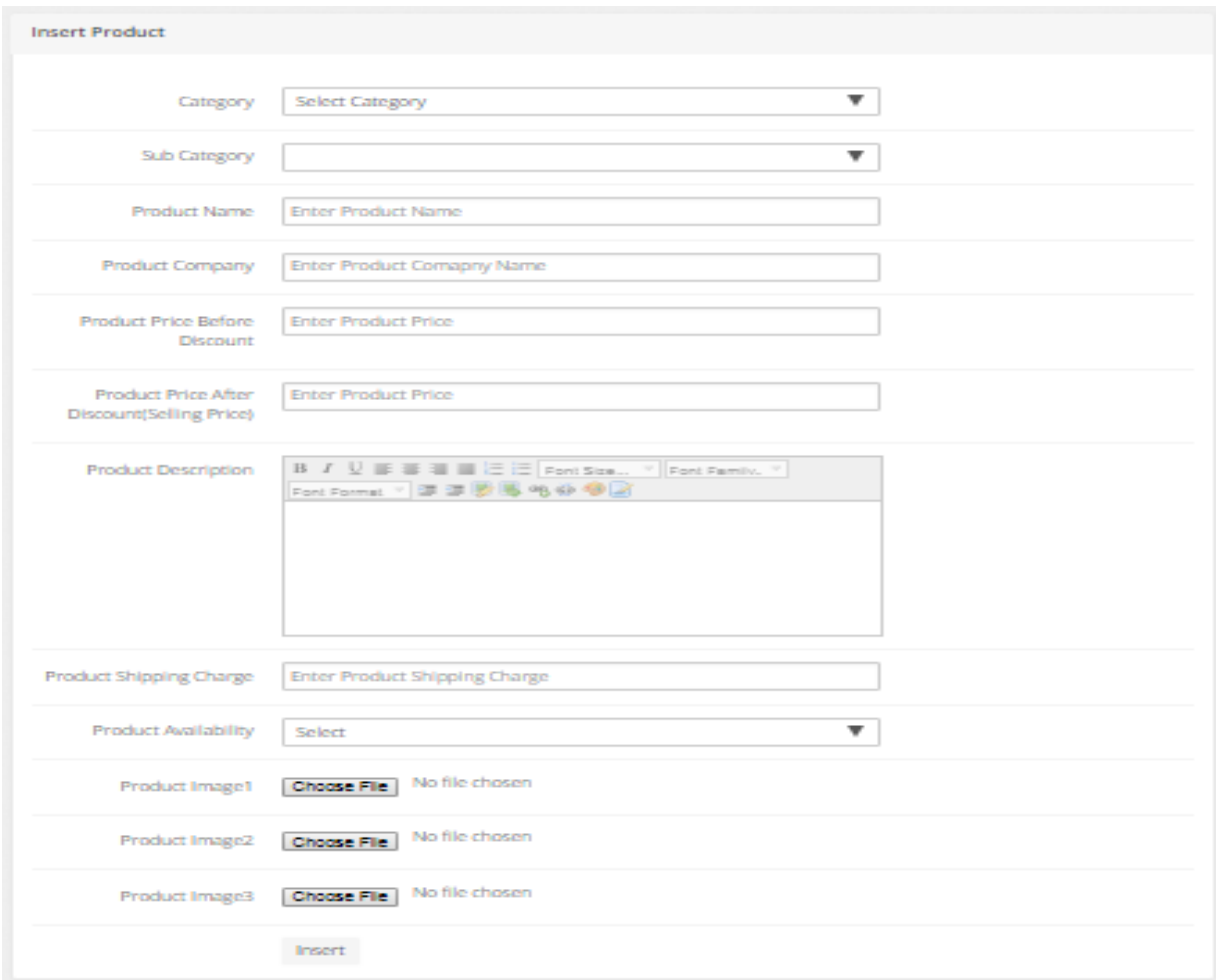

Figure 16: (Add Cattle)

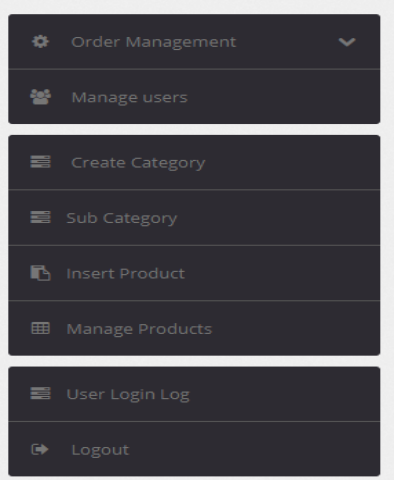

Manage Products

\begin{tabular}{|c|c|c|c|}
\hline \multirow{2}{*}{$\begin{array}{l}\text { Show } \\
\#\end{array}$} & \multicolumn{2}{|l|}{10} & - entries \\
\hline & Product Name & Category & Subcategory \\
\hline 1 & sahiwali & Cow & Sahiwal \\
\hline 2 & Freezan & Cow & Freezan \\
\hline 3 & MILKY & Cow & Australian \\
\hline 4 & Bull & Cow & Bull \\
\hline 5 & Neeli & Buffelo & Neeli \\
\hline 6 & Desi & Buffelo & Desi \\
\hline 7 & desi & Buffelo & Desi \\
\hline 8 & Bakra & Goat & Desi \\
\hline 9 & lailpuri & Goat & Lailpur \\
\hline 10 & sheep & Goat & Sheep \\
\hline
\end{tabular}

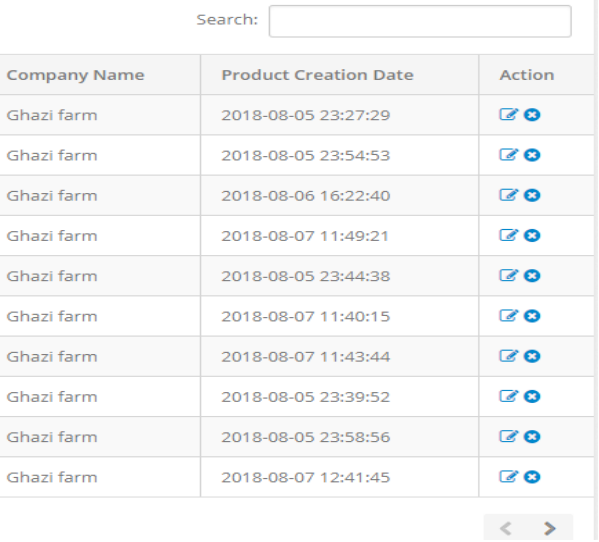

Figure 17: ( Manage Products)

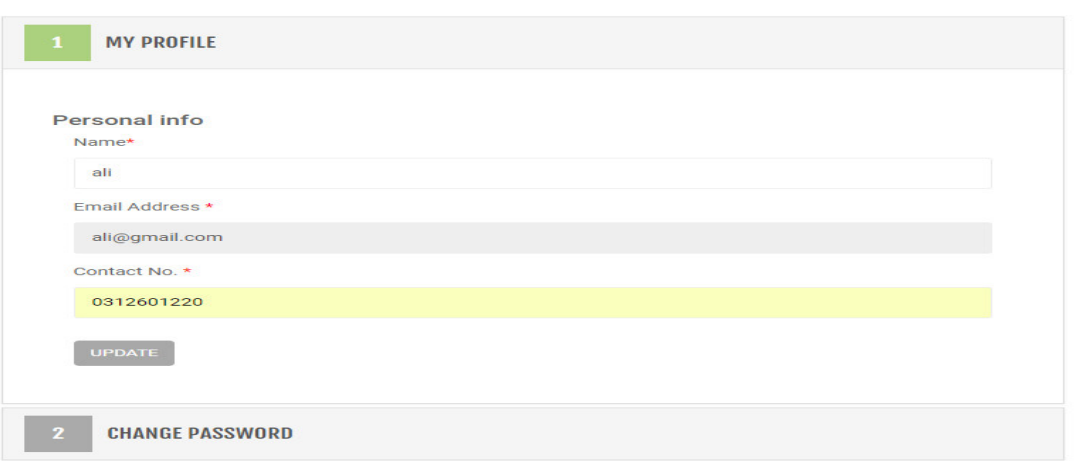

My Account

Figure 18: (Customer profile) 

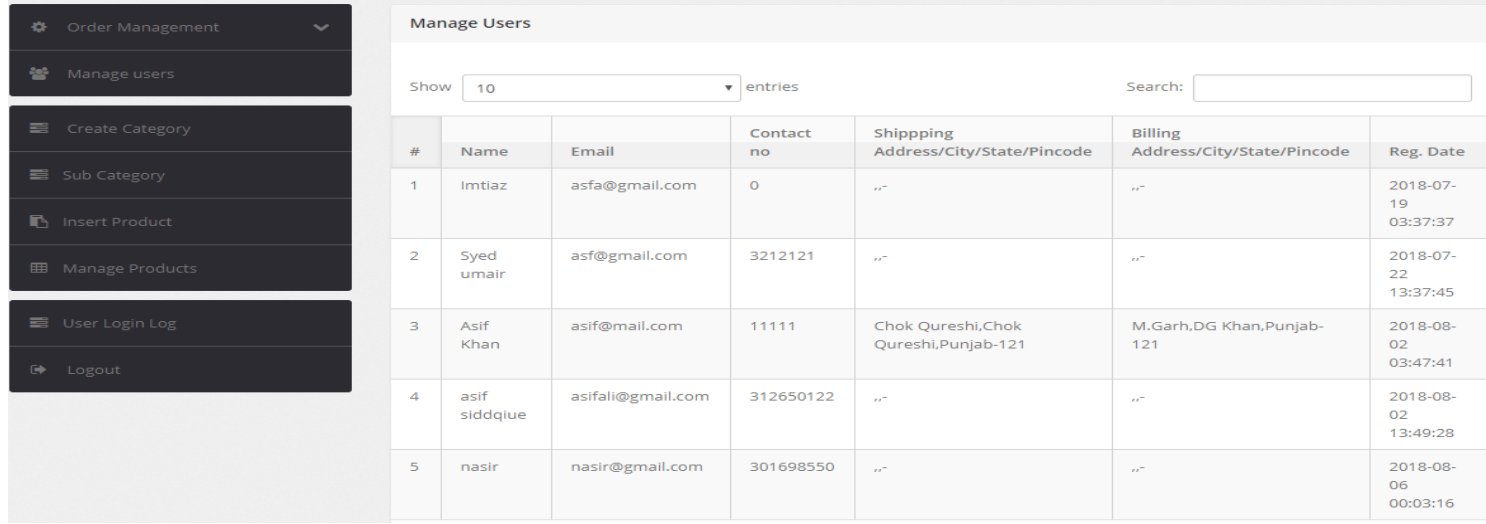

Figure 19: (User Information)
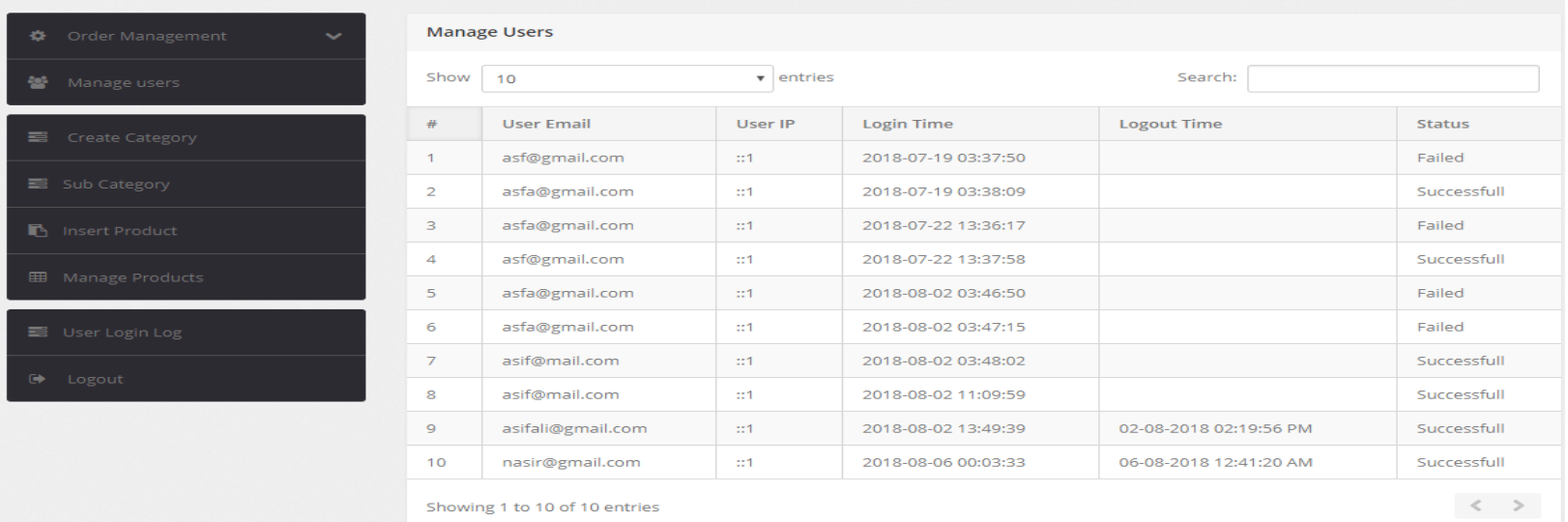

Figure 20: (user login log)

\section{Conclusion}

The Cattle Management system is concerned with enhanced, secure and authorized availability of Ghazi Farm with the fully utilization of the internet (online connectivity) and combined talent and skills do entire workforce of the Farm. Ghazi Farm system must today reinvent itself to cope with the demands of a global economy. In which buyer purchase the cattle but also the facility that is seller can also sale their cattle here.

\section{References and Bibliography:}

[1] "w3schools," [Online]. Available: http://www.w3schools.com/php/. [Accessed 2612017 ].

[2] "C, B. Relational Approach. Conceptual database Design[1994]".

[3] " PHP " [Online]. Available: http://php.net/manual/en/intro-whatis.php. [Accessed 1510 2017].

[4] L. Welling and L. Thomson, PHP and MySQL Web Development, 4th ed., 2008: Addison-Wesley Professional.

[5] R. Nixon, Learning PHP, MySQL \& JavaScript, 4th ed., O'Reilly Media, 2014. 